\title{
Suppressor of cytokine signaling (SOCS) genes are downregulated in breast cancer
}

\author{
Soudeh Ghafouri-Fard ${ }^{1}$, Vahid Kholghi Oskooei ${ }^{1}$, Iman Azari ${ }^{1}$ and Mohammad Taheri ${ }^{2,3^{*}}$ (D)
}

\begin{abstract}
Background: The suppressor of cytokine signaling (SOCS) family of proteins are inhibitors of the cytokine-activated Janus kinase/signal transducers and activators of transcription (JAK/STAT) signaling pathway. We aimed at evaluation of expression of SOCS genes in breast cancer.

Methods: We evaluated expression of SOCS1-3 and SOCS5 genes in breast cancer samples compared with the corresponding adjacent non-cancerous tissues (ANCTs).

Results: All assessed SOCS genes were significantly downregulated in tumoral tissues compared with ANCTs. SOCS1 and SOCS2 genes were significantly overexpressed in higher grade samples, but SOCS3 had the opposite trend. Significant correlations were found between expression levels of SOCS genes. The SOCS1 and SOCS2 expression levels had the best specificity and sensitivity values respectively for breast cancer diagnosis.
\end{abstract}

Conclusion: The current study provides further evidence for contribution of SOCS genes in breast cancer.

Keywords: Suppressor of cytokine signaling, Breast cancer, Expression

\section{Introduction}

The suppressor of cytokine signaling (SOCS) family of proteins have been recognized as potent inhibitors of the cytokine-activated Janus kinase/signal transducers and activators of transcription (JAK/STAT) signaling pathway through which they also suppress cytokine signal transduction [1]. Apart from their role in the regulation of immune responses, tumor suppressor functions have been demonstrated for certain members of this family in various tissues. For instance, SOCS1 impedes proliferation signals relayed by several oncogenes in the hematopoietic lineage [2] and hepatic tissue [3]. Moreover, hypermethylation of SOCS1 promoter has been shown in hepatocellular carcinoma [3], cervical cancer [4], and ovarian and breast cancer cells [5]. Such data implies that aberrant downregulation of SOCS genes might participate in the development of breast cancer as well. However, Evans et al. have shown upregulation of several members of SOCS family in

\footnotetext{
*Correspondence: mohammad_823@yahoo.com

${ }^{2}$ Student Research Committee, Shahid Beheshti University of Medical Sciences, Tehran, Iran

${ }^{3}$ Urogenital Stem Cell Research Center, Shahid Beheshti University of Medical Sciences, Tehran, Iran

Full list of author information is available at the end of the article
}

MCF-7 and HCC1937, two cell lines that are regarded as prototypic breast cancer cell types. Moreover, they have demonstrated responsiveness of SOCS1 and SOCS3 promoters to regulation by cytokine or growth factor signals in spite of hypermethylation state of these promoters in these two cell lines [6]. Sutherland et al. have reported the inhibitory role of SOCS1 and SOCS2 but not SOCS3 on the growth of breast cancer cells and suggested hypermethylation of these genes as a mechanism for intensifying cytokine responsiveness and tumorigenesis process in breast tissue [5]. However, considering the difference in the expression of microenvironment-related genes in cancer cell lines and clinical samples, the data regarding expression pattern of SOCS genes in cell lines can be hardly adopted for clinical samples. The results of expression analysis of SOCS genes in clinical samples are inconsistent. Although Sasi et al. reported higher expression of SOCS1 mRNA in breast tumor samples obtained from patients with earlier tumor stage and better survival [7], Raccurt et al. demonstrated constant higher expression of SOCS1-3 in tumor cells compared with normal adjacent epithelial and connective tissues [8]. Consistent with the results of the former study,

(C) The Author(s). 2018 Open Access This article is distributed under the terms of the Creative Commons Attribution 4.0 International License (http://creativecommons.org/licenses/by/4.0/), which permits unrestricted use, distribution, and 
expression of SOCS1 protein in breast cancer tissues has been associated with lower risk of identification of circulating tumor cells in the peripheral blood [9]. Based on the importance of SOCS-based strategies in treatment of cancer [10], assessment of expression of SOCS genes in clinical samples obtained from breast cancer patients is of practical value. Consequently, we designed the current study to evaluate the expression of SOCS1-3 and SOCS5 genes in invasive ductal carcinoma of the breast compared with the corresponding adjacent non-cancerous tissues (ANCTs).

\section{Material and methods \\ Patients}

Fifty-four patients with definite diagnosis of invasive ductal carcinoma of the breast participated in the study. The inclusion criteria were histopathological confirmation of invasive ductal carcinoma and availability of clinical data. Patients with other types of breast cancer and familial breast cancer and those who received prior chemo/radiotherapy were excluded from the study. The research protocol was approved by the ethical committee of Shahid Beheshti University of Medical Sciences. All methods were performed in accordance with the relevant guidelines and regulations. Informed written consent was obtained from all patients. Tumoral tissues and ANCTs were excised from all patients during surgery in Sina and Farmanieh hospitals. All tissue samples were transferred in liquid nitrogen to the genetic laboratory and stored in $-80^{\circ}$ $\mathrm{C}$ until gene expression experiments. Medical records of patients were assessed, and the relevant data was collected for correlation analysis.

\section{Expression analysis}

Relative expressions of SOCS genes were assessed in tumoral tissues and ANCTs using quantitative real-time PCR technique. Briefly, total RNA was extracted from tissue samples using TRIzol ${ }^{\text {Tm }}$ Reagent (Invitrogen, Carlsbad, CA, USA), and cDNA was synthesized by using RevertAid First Strand cDNA Synthesis Kit (TaKaRa, Japan). TaqMan Fast Universal PCR Master Mix (Applied Biosystems, Foster City, USA) was used for expression analysis of genes. Expressions of genes were normalized to expression of hypoxanthine-guanine phosphoribosyl transferase (HPRT). The nucleotide sequences of primers are shown in Table 1.

All experiments were performed in duplicate in the rotor gene 6000 Corbett Real-Time PCR System.

\section{Estrogen receptor (ER)/progesterone receptor (PR)}

ER/PR status was acquired from patients' medical histories which were performed by immunohistochemical (IHC) staining. Staining of $\geq 5 \%$ of tumor cell nuclei was described as positive, while staining of lower percentages was reported as negative.

\section{HER2/neu}

HER2/neu results were acquired from the medical reports of patient and were performed by IHC. Results of 0 to $2+$ were regarded as negative and $3+$ was considered as positive.

\section{Ki-67}

$\mathrm{Ki}-67$ status was assessed using IHC assays with the anti-human Ki-67 monoclonal antibody MIB1. The percentage of positively stained malignant cells among the

Table 1 The nucleotide sequences of primers used for expression analysis

\begin{tabular}{|c|c|c|c|}
\hline Gene name & Primer and probe sequence & Primer and probe length & Product length \\
\hline \multirow[t]{3}{*}{ HPRT1 } & F: AGCCTAAGATGAGAGTTC & 18 & \multirow[t]{3}{*}{88} \\
\hline & R: CACAGAACTAGAACATTGATA & 21 & \\
\hline & FAM-CATCTGGAGTCCTATTGACATCGC-TAMRA & 24 & \\
\hline \multirow[t]{3}{*}{ SOCS1 } & F: TGGCCCCTTCTGTAGGATGG & 20 & \multirow[t]{3}{*}{109} \\
\hline & R: GGAGGAGGAAGAGGAGGAAGG & 21 & \\
\hline & FAM-TGGCCCCTTCTGTAGGATGG-TAMRA & 20 & \\
\hline \multirow[t]{3}{*}{ socs2 } & F: ACGCGAACCCTTCTCTGACC & 20 & \multirow[t]{3}{*}{99} \\
\hline & R: CATTCCCGGAGGGCTCAAGG & 20 & \\
\hline & FAM-CTCGGGCGGCCACCTGTCTITGC-TAMRA & 23 & \\
\hline \multirow[t]{3}{*}{ socs3 } & F: GTGGAGAGGCTGAGGGACTC & 20 & \multirow[t]{3}{*}{111} \\
\hline & R: GGCTGACATTCCCAGTGCTC & 20 & \\
\hline & FAM-CACCAAGCCAGCCCACAGCCAGG-TAMRA & 23 & \\
\hline \multirow[t]{3}{*}{ socs5 } & F: GTGACTCGGAAGAGGATACAACC & 23 & \multirow[t]{3}{*}{91} \\
\hline & R: CTAACATGGGTATGGCTGTCTCC & 23 & \\
\hline & FAM-CGCTGCTTCTGCCTCCGTGACTGC-TAMRA & 24 & \\
\hline
\end{tabular}


total number of malignant cells was calculated. The results were reported as positive vs. negative.

\section{Statistical analysis}

Student's paired and unpaired $t$ tests were used for analysis of differences in gene expression between paired and unpaired samples. The association between clinicopathological data and transcript levels of each gene was assessed using the chi-square test. Tukey's honest significance test was used to find the difference between mean values of transcript levels between different groups. The expression fold change was measured using the efficiency corrected calculation models. The pairwise correlation between relative transcripts levels of genes was measured using the regression model. For all statistical tests, the level of significance was set at $P<0.05$. The receiver operating characteristic (ROC) curve was plotted to evaluate the rightness of gene expression levels for differentiating tumoral vs. ANCTs. In order to evaluate gene expression probability cutoff, the Youden index (j) was used to maximize the difference between sensitivity (true-positive rate) and 1-specificity (false-positive rate). The precision of each marker for diagnosis of malignancy status was scored based on the area under curve (AUC) values using the following assumption: 0.90-1 = excellent (A), $0.80-0.90=\operatorname{good}(\mathrm{B}), 0.70-0.80$ = fair $(\mathrm{C}), 0.60-0.70=$ poor $(\mathrm{D})$, and $0.50-0.60=$ fail $(\mathrm{F})$.

\section{Results}

\section{General demographic data of patients}

General demographic data of patients are shown in Table 2.

Relative expression of SOCS in tumoral tissues vs. ANCTs All assessed SOCS genes were significantly downregulated when comparing total tumoral tissues with total ANCTs (SOCS1: expression ratio $=0.47, \quad P=0.033$; SOCS2: expression ratio $=0.38, P=0.008$; SOCS3: expression ratio $=0.47, P=0.027$; and SOCS5: expression ratio $=0.35, P=0.001$ ). Figure 1 shows relative expression of SOCS genes in tumoral tissues and ANCTs.

\section{Association between relative expression of genes and patients' clinicopathological data}

We compared the expression level of each gene in each tumoral tissue vs. its corresponding ANCT and categorized patients based on these values to upregulation and downregulation groups. Next, we assessed associations between clinicopathological data and relative expressions of genes. No significant associations were found between the relative expression of genes in tumoral tissues and the ANCTs and patients' clinicopathological data. Table 3 shows the results of association analysis between relative expressions of genes in tumoral tissues and ANCTs and patients' clinicopathological data.
Table 2 General demographic data of study participants

\begin{tabular}{|c|c|}
\hline Variables & Values \\
\hline Age (years) (mean $\pm S D)$ & $51.79 \pm 13.54(29-81)$ \\
\hline Menarche age (years) (mean \pm SD) & $13 \pm 1.65(10-18)$ \\
\hline Menopause age (years) (mean \pm SD) & $44.91 \pm 14.91(38-60)$ \\
\hline First pregnancy age (years) (mean \pm SD) & $18.04 \pm 8.36(14-32)$ \\
\hline Breast feeding duration (months) (mean $\pm S D$ ) & $41.62 \pm 34.1(3-120)$ \\
\hline \multicolumn{2}{|l|}{ Cancer stage (\%) } \\
\hline । & 30.8 \\
\hline$\|$ & 28.8 \\
\hline III & 30.8 \\
\hline IV & 9.6 \\
\hline \multicolumn{2}{|l|}{ Overall grade (\%) } \\
\hline I & 17 \\
\hline$\|$ & 49 \\
\hline III & 34 \\
\hline \multicolumn{2}{|l|}{ Mitotic rate (\%) } \\
\hline । & 45.2 \\
\hline$\|$ & 42.9 \\
\hline III & 11.9 \\
\hline \multicolumn{2}{|l|}{ Tumor size (\%) } \\
\hline$<2 \mathrm{~cm}$ & 32 \\
\hline$\geq 2 \mathrm{~cm},<5 \mathrm{~cm}$ & 66 \\
\hline$\geq 5 \mathrm{~cm}$ & 2 \\
\hline \multicolumn{2}{|l|}{ Estrogen receptor (\%) } \\
\hline Positive & 87.8 \\
\hline Negative & 12.2 \\
\hline \multicolumn{2}{|l|}{ Progesterone receptor (\%) } \\
\hline Positive & 77.1 \\
\hline Negative & 22.9 \\
\hline \multicolumn{2}{|l|}{ Her2/neu expression (\%) } \\
\hline Positive & 25 \\
\hline Negative & 75 \\
\hline \multicolumn{2}{|l|}{ Ki67 expression (\%) } \\
\hline Positive & 100 \\
\hline Negative & 0 \\
\hline
\end{tabular}

Moreover, we compared relative expression of each gene in tumoral samples between clinicopathologicalbased categories (Table 4). SOCS1 and SOCS2 genes were significantly overexpressed in grade 2 samples compared with grade 1 samples ( $P$ values of 0.004 and 0.04 respectively), but SOCS3 had the opposite trend $(P=0.01)$. Moreover, expressions of SOCS1 and SOCS2 genes were significantly higher in grade 3 samples compared with grade 1 samples $(P$ values of 0.007 and 0.05 respectively). No significant difference 


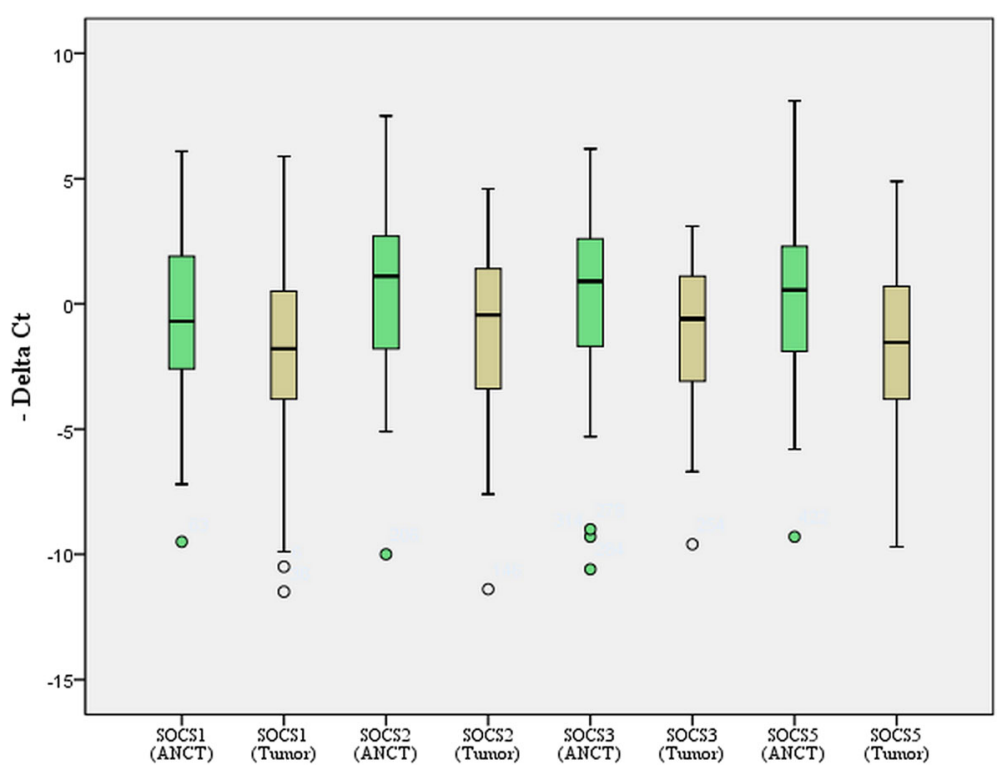

Fig. 1 The relative expression of SOCS genes in tumoral tissues and ANCTs ( $Y$-axis shows $C T_{\text {reference gene }}-C T$ target gene)

was found in expressions of other genes between other clinicopathological-based categories.

\section{Correlation between relative expressions of genes}

We evaluated correlations between expression levels of genes in both tumoral tissues and ANCTs. Significant correlations were found between expression of SOCS genes both in ANCTs and in tumoral tissues except for lack of correlation between SOCS2 and SOCS5 in tumoral tissues (Table 5).

\section{Partial correlation between expression of genes and patients' age and tumor grade}

We also assessed the correlation between expression of genes and patients' age and tumor grade after controlling the effects of each variable. After controlling the effects of confounding factors, no significant correlation was found between expression of genes and patients' age or tumor grade (Table 6).

\section{ROC curve analysis}

Based on the ROC curve analysis results, the SOCS1 and SOCS2 expression levels had the best specificity and sensitivity values respectively for breast cancer diagnosis (Fig. 2). Combination of transcript levels of all SOCS genes improved the AUC value, but such value did not reach the acceptable threshold. Table 7 shows the details of ROC curve analysis.

\section{Discussion}

SOCS proteins potently regulate the intensity and extent of STAT signals. Absence of SOCS functions would lead to constitutive expression of STAT pathways which in turn triggers cellular transformation, tumor cell invasion, and metastasis [11]. STAT proteins have established role in the development of breast cancer. Downregulation of STAT3 and STAT5a/b has been suggested as a mechanism for anti-proliferative effects of some anti-cancer agents in breast cancer cells [12]. In the present study, we demonstrated significant downregulation of SOCS13 and SOCS5 genes in breast cancer tissues compared with ANCTs which is in line with the previous findings regarding the role of SOCS proteins in the regulation of STAT proteins and the contribution of STATs in the pathogenesis of breast cancer. Downregulation of SOCS1 has been demonstrated in numerous malignancies such as prostate cancer, hepatocellular carcinoma, laryngeal carcinoma, multiple myeloma, acute myeloid leukemia, pancreatic cancer, and lymphoma [13]. However, the results of previous studies regarding expression of SOCS genes in breast cancer are inconsistent. Raccurt et al. have previously assessed the expression of SOCS1-3 genes in 17 breast carcinomas, 3 ANCTs, and 10 breast cancer lines and demonstrated higher expression of SOCS1-3 proteins within in situ ductal carcinomas and infiltrating ductal carcinomas compared with normal breast samples. In situ hybridization also confirmed overexpression of SOCS1-3 transcripts in both tumor tissue and reactive stroma. They suggested that such overexpression might reflect the host/tumor response or be induced secondary to autocrine/paracrine release of growth hormone and prolactin [8]. The inconsistency between our results and Raccurt et al. study can be explained by the low number of samples in their study. As 


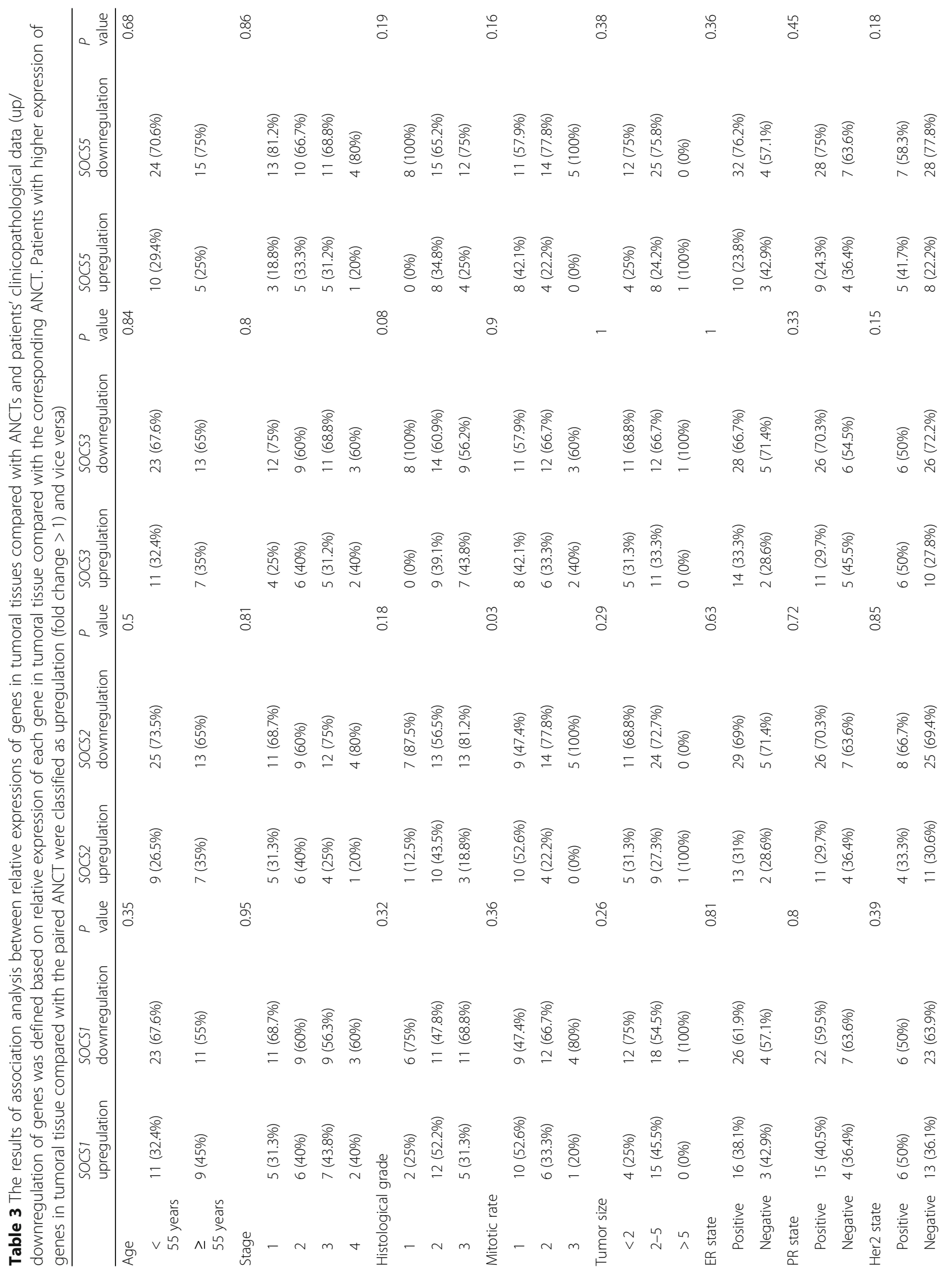




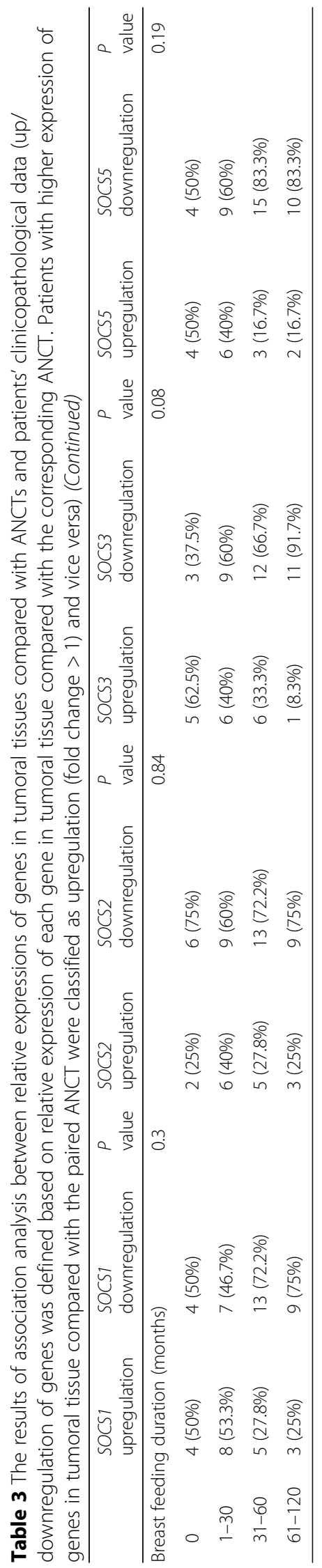


Table 4 Comparison of expression levels of SOCS genes in tumoral tissue of breast cancer patients between clinicopathological-

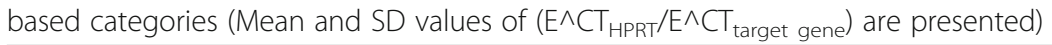

\begin{tabular}{|c|c|c|c|c|c|c|c|c|}
\hline & $\begin{array}{l}\text { SOCS1 expression } \\
\text { (mean (SD)) }\end{array}$ & $P$ value & $\begin{array}{l}\text { SOCS2 expression } \\
\text { (mean (SD)) }\end{array}$ & $P$ value & $\begin{array}{l}\text { SOCS3 expression } \\
\text { (mean (SD)) }\end{array}$ & $P$ value & $\begin{array}{l}\text { SOCS5 expression } \\
\text { (mean (SD)) }\end{array}$ & $P$ value \\
\hline \multicolumn{9}{|l|}{ Age } \\
\hline $\begin{array}{l}<55 \text { years vs. } \\
\geq 55 \text { years }\end{array}$ & $\begin{array}{l}496.1(2.6) \text { vs. } \\
592.9(2.6)\end{array}$ & 0.88 & $\begin{array}{l}1.5 \text { (7.9) vs. } \\
10.9(17.2)\end{array}$ & 0.43 & $\begin{array}{l}199.5(542.6) \text { vs. } \\
84.7(372.8)\end{array}$ & 0.4 & $\begin{array}{l}16.7(44.9) \mathrm{vs} . \\
1.1(4.9)\end{array}$ & 0.33 \\
\hline \multicolumn{9}{|l|}{ ER status } \\
\hline ER (+) vs. ER (-) & $\begin{array}{l}675.4(2.9) \text { vs. } \\
0.6(0.8)\end{array}$ & 0.55 & $\begin{array}{l}1.2(7.1) \text { vs. } \\
5.1(7.7)\end{array}$ & 0.64 & $\begin{array}{l}192.5(545.1) \text { vs. } \\
55.1(127.2)\end{array}$ & 0.51 & $\begin{array}{l}537.3(3.3) \text { vs. } \\
1.5(1.5)\end{array}$ & 0.68 \\
\hline \multicolumn{9}{|l|}{ PR status } \\
\hline PR (+) vs. PR (-) & $\begin{array}{l}766.1(3.1) \text { vs. } \\
2.5(6.9)\end{array}$ & 0.42 & $\begin{array}{l}1.4(7.5) \text { vs. } \\
4(5.9)\end{array}$ & 0.53 & $\begin{array}{l}216.6(577.2) \text { vs. } \\
41.5(102.1)\end{array}$ & 0.08 & $\begin{array}{l}609.9(3.6) \text { vs. } \\
1.2(1.3)\end{array}$ & 0.58 \\
\hline \multicolumn{9}{|l|}{ HER2 status } \\
\hline HER2 (+) vs. HER2 (-) & $\begin{array}{l}20(25.1) \text { vs. } \\
781.5(3.1)\end{array}$ & 0.41 & $\begin{array}{l}10.3(17.8) \text { vs. } \\
1.4(7.6)\end{array}$ & 0.51 & $\begin{array}{l}223.3 \text { (763) vs. } \\
160.9(411.2)\end{array}$ & 0.71 & $\begin{array}{l}3.4(5.6) \text { vs. } \\
626(3.6)\end{array}$ & 0.56 \\
\hline \multicolumn{9}{|l|}{ Tumor grade } \\
\hline Grade 1 vs. 2 & $\begin{array}{l}3.4(6.2) \text { vs. } \\
13.7(23.4)\end{array}$ & 0.004 & $\begin{array}{l}6.5(1.6) \mathrm{vs.} \\
13.8(20.6)\end{array}$ & 0.04 & $\begin{array}{l}596 \text { (735) vs. } \\
25.7(63.9)\end{array}$ & 0.01 & $\begin{array}{l}2.8(7.7) \text { vs. } \\
3.8(7.1)\end{array}$ & 0.08 \\
\hline Grade 1 vs. 3 & $\begin{array}{l}3.4(6.2) \text { vs. } \\
8.1(19.2)\end{array}$ & 0.007 & $\begin{array}{l}6.5(1.6) \text { vs. } \\
10.8(17.6)\end{array}$ & 0.05 & $\begin{array}{l}596(735) \text { vs. } \\
194.5(659.3)\end{array}$ & 0.1 & $\begin{array}{l}2.8(7.7) \text { vs. } \\
2.3(3.9)\end{array}$ & 0.1 \\
\hline Grade 2 vs. 3 & $\begin{array}{l}13.7(23.4) \text { vs. } \\
8.1(19.2)\end{array}$ & 1 & $\begin{array}{l}13.8(20.6) \text { vs. } \\
10.8(17.6)\end{array}$ & 1 & $\begin{array}{l}25.7(63.9) \text { vs. } \\
194.5(659.3)\end{array}$ & 0.5 & $\begin{array}{l}3.8(7.1) \text { vs. } \\
2.3(3.9)\end{array}$ & 1 \\
\hline
\end{tabular}

we demonstrated in our study, expressions of SOCS genes do not follow a similar pattern in all patients. For instance, while SOCS1 was downregulated in about two third of breast cancer tissues compared with the corresponding ANCTs, it was upregulated in the remaining samples. This was also true for other SOCS genes. Contrary to Raccurt et al., Sasi et al. have assessed expression of SOCS1-7 transcript levels in 127 breast cancer tissues and 31 ANCTs using real-time PCR and reported no significant difference in their expression between tumoral tissues and ANCTs [7]. Failure to find difference in expression levels of genes between tumoral tissues and ANCTs might be due to dissimilar number of samples in each group. However, they found inverse association between SOCS1, 4, 5, 6, and SOCS7 expressions and TNM stage. Notably, they reported significant

Table 5 Coefficients of determination ( $R$ square) values between expression levels of genes in tumoral tissues and ANCTS

\begin{tabular}{lllll}
\hline & & SOCS5 & SOCS3 & SOCS2 \\
\hline SOCS1 & Tumor & $0.59^{* *}$ & $0.65^{* *}$ & $0.81^{* *}$ \\
& ANCT & $0.96^{* *}$ & $0.85^{* *}$ & $0.52^{* *}$ \\
SOCS2 & Tumor & 0.02 & $0.5^{* *}$ & \\
& ANCT & $0.69^{* *}$ & $0.88^{* *}$ & \\
& Tumor & $0.43^{*}$ & & \\
& ANCT & $0.95^{* *}$ & & \\
\hline
\end{tabular}

Data show partial correlation as controlled for age ${ }^{*}$ Correlation is significant at $P<0.05$ level, ${ }^{* *}$ correlation is significant at $P<0.01$ level associations between higher levels of certain SOCS genes and disease-free or overall survival [7].

Our results regarding global downregulation of SOCS2 in tumoral samples compared with ANCTs are in line with Farabegoli et al. study which demonstrated a role for SOCS2 downregulation in the enhancement of cell proliferation and tumor growth in breast cancer [14]. They also demonstrated positive association between SOCS2 protein expression and low grade, low nuclear grade, and p27 protein [14] which is not consistent with our results. Haffner et al. also demonstrated favorable prognostic value of high SOCS2 expression in primary breast tumors [15].

We hypothesize that SOCS downregulation in breast cancer samples as revealed in our study might result in constitutive expression of STAT pathways. Higher expression of STAT genes might contribute to several aspects of tumorigenesis such as cellular transformation, invasion, and metastasis. Alternatively, based on the reported role of SOCS proteins in inhibition of mutant Jak2 and suppression of cytokine-independent signaling [16], downregulation of SOCS genes in breast cancer tissues may trigger some cytokine-independent pathways resulting in cell transformation.

Although we did not find any association between expression of SOCS genes and TNM stage, we found higher levels of SOCS1 and SOCS2 genes in grade 2 and 3 samples compared with grade 1 samples but lower levels of SOCS3 in grade 1 samples compared with grade 2 samples. Sasi et al. have previously shown 
Table 6 Partial correlation between expression of genes and patients' age and tumor grade

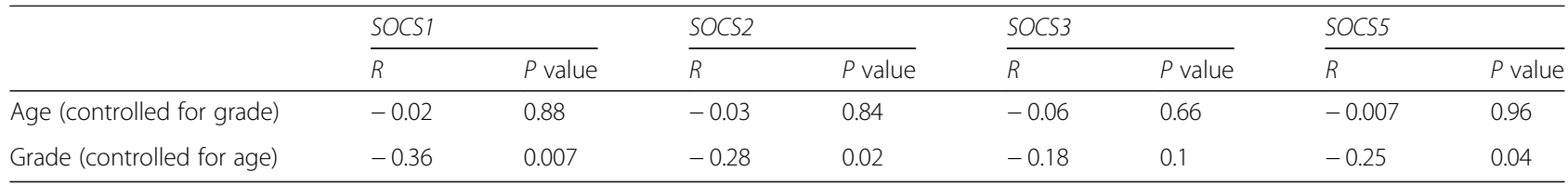

downregulation of SOCS7 expression in higher tumor grades [7]. The observed differences in expression of SOCS genes between different pathological grades might reflect specific roles of SOCS genes in certain grades of malignancy. One might classify SOCS genes to certain groups based on their relative expression in different grades of breast cancer. However, future studies are needed to clarify the practical significance of such observation.

The reported downregulation of SOCS3 in our study is in line with the Barclay et al. study which demonstrated the antiproliferative role of this gene via inhibition of STAT3 expression and suppression of STAT5 phosphorylation in breast cancer cells [17].

We also demonstrated significant downregulation of SOCS5 in tumoral tissues compared with ANCTs. Kario et al. have previously shown overexpression of SOCS5 in cells following treatment with epidermal growth factor (EGF). They also reported the effect of SOCS5 on downregulation of epidermal growth factor receptor (EGFR) expression through enhancement of EGFR degradation [18]. Considering the role of EGFR and its downstream pathway in regulation of epithelial-mesenchymal transition, migration, and tumor invasion in breast cancer and the availability of drugs that target this pathway [19], alterations in the expression of SOCS5 in breast cancer might be involved in the response of patients to such targeted therapies.

The observed downregulation of SOCS genes in breast cancer tissues compared with ANCTs might be due to either epigenetic or genetic changes. Sutherland et al. have reported SOCS1 promoter hypermethylation in $9 \%$ of breast cancer samples [5]. On the other hand, deleterious SOCS1 mutations have been detected in both primary mediastinal B-cell lymphoma and classical Hodgkin lymphoma [20]. Considering the role of growth hormone and prolactin in regulation of SOCS genes expression [8, 17], any change in the secretion of these hormones in the tumor microenvironment might also alter SOCS expression.

We also demonstrated significant correlations between expression of SOCS genes both in ANCTs and in tumoral tissues except for lack of correlation between SOCS2 and SOCS5 in tumoral tissues which suggest the presence of a similar regulatory mechanism for their expression.

\section{Conclusion}

In spite of significant difference in expression levels of SOCS genes between tumoral tissues and ANCTs, none

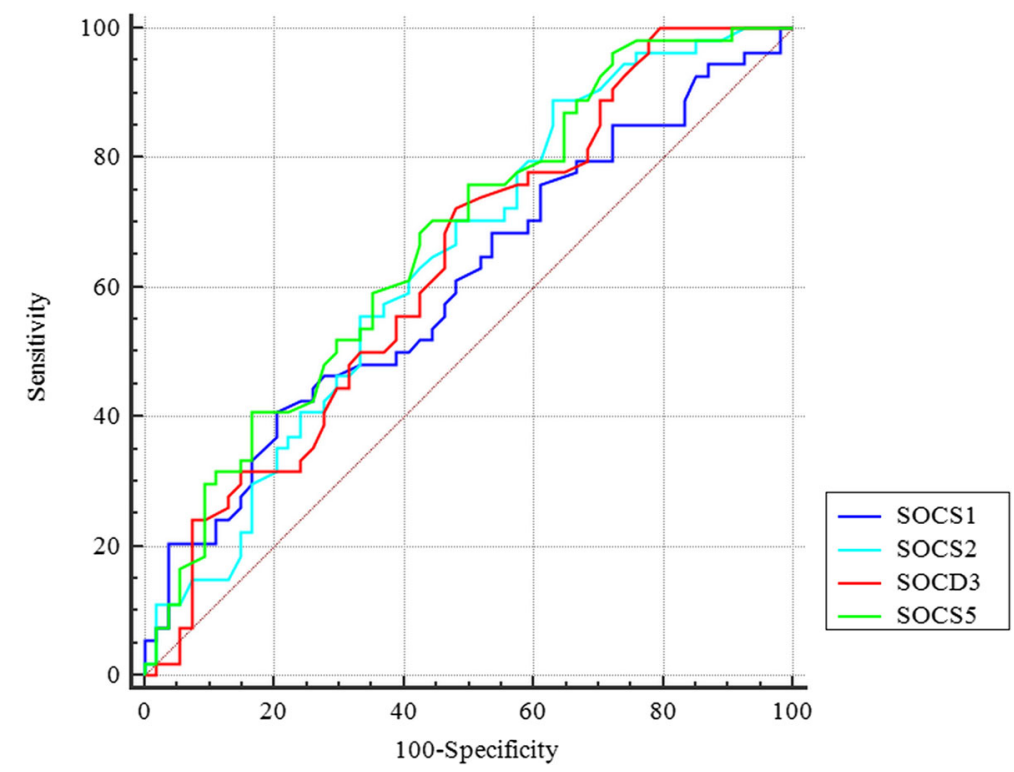

Fig. 2 ROC curve for assessment of SOCS genes expression levels as diagnostic markers for breast cancer 
Table 7 The results of ROC curve analysis

\begin{tabular}{lllllll}
\hline & Estimate criterion & AUC & $\rho^{a}$ & Sensitivity & Specificity & $P$ value \\
\hline SOCS1 & $>2.7$ & 0.6 & 0.2 & 40.7 & 79.6 & 0.05 \\
SOCS2 & $>-2.4$ & 0.64 & 0.25 & 88.9 & 37 & 0.007 \\
SOCS3 & $>-0.9$ & 0.63 & 0.24 & 72.2 & 51.9 & 0.01 \\
SOCS5 & $>-0.8$ & 0.67 & 0.25 & 75.9 & 50 & 0.0009 \\
Combination of all genes & $\leq 0.5$ & 0.68 & 0.35 & 64.8 & 70.4 & 0.0004 \\
\hline
\end{tabular}

Estimate criterion: optimal cutoff point for gene expression

${ }^{a}$ Youden index,

${ }^{\mathrm{b}}$ Significance level $P$ (area $=0.5$ )

of SOCS genes had adequate sensitivity and specificity to be used as a diagnostic biomarker.

Taken together, in spite of frequently reported alterations of SOCS genes in human malignancies, the data regarding expression of these genes in breast cancer is inconclusive which necessitates design of further studies with larger sample sizes to elaborate their function in this type of human cancer.

\section{Acknowledgements}

The current study was supported by a grant from Shahid Beheshti University of Medical Sciences.

\section{Funding}

Not applicable

\section{Availability of data and materials}

The analyzed data sets generated during the study are available from the corresponding author on reasonable request.

\section{Authors' contributions}

MT and SG-F supervised the study. IA performed the laboratory assessment. VKO analyzed the data. All authors read and approved the final manuscript.

\section{Ethics approval and consent to participate}

All procedures performed in studies involving human participants were in accordance with the ethical standards of the institutional and/or national research committee and with the 1964 Helsinki declaration and its later amendments or comparable ethical standards.

\section{Consent for publication}

Not applicable

\section{Competing interests}

The authors declare they have no competing interests.

\section{Publisher's Note}

Springer Nature remains neutral with regard to jurisdictional claims in published maps and institutional affiliations.

\section{Author details}

'Department of Medical Genetics, Shahid Beheshti University of Medical Sciences, P.O.Box: 19857-17443, Tehran, Iran. ${ }^{2}$ Student Research Committee, Shahid Beheshti University of Medical Sciences, Tehran, Iran. ${ }^{3}$ Urogenital Stem Cell Research Center, Shahid Beheshti University of Medical Sciences, Tehran, Iran.

Received: 28 August 2018 Accepted: 12 November 2018 Published online: 19 November 2018

\section{References}

1. Cooney RN. Suppressors of cytokine signaling (SOCS): inhibitors of the JAK STAT pathway. Shock. 2002;17:83-90.
2. Rottapel R, llangumaran S, Neale C, La Rose J, Ho JM, Nguyen MH, Barber D, Dubreuil $P$, de Sepulveda $P$. The tumor suppressor activity of SOCS-1. Oncogene. 2002;21:4351-62.

3. Yoshikawa H, Matsubara K, Qian GS, Jackson P, Groopman JD, Manning JE, Harris CC, Herman JG. SOCS-1, a negative regulator of the JAKJSTAT pathway, is silenced by methylation in human hepatocellular carcinoma and shows growth-suppression activity. Nat Genet. 2001;28:29-35.

4. Kim M-H, Kim M-S, Kim W, Kang MA, Cacalano NA, Kang S-B, et al. Suppressor of cytokine signaling (SOCS) genes are silenced by DNA hypermethylation and histone deacetylation and regulate response to radiotherapy in cervical cancer cells. PloS one. 2015;10(4):e0123133.

5. Sutherland KD, Lindeman GJ, Choong DY, Wittlin S, Brentzell L, Phillips W, et al. Differential hypermethylation of SOCS genes in ovarian and breast carcinomas. Oncogene. 2004;23(46):7726-33.

6. Evans MK, Yu CR, Lohani A, Mahdi RM, Liu X, Trzeciak AR, et al. Expression of SOCS1 and SOCS3 genes is differentially regulated in breast cancer cells in response to proinflammatory cytokine and growth factor signals. Oncogene. 2007;26(13):1941-8.

7. Sasi W, Jiang WG, Sharma A, Mokbel K. Higher expression levels of SOCS 1,3,4,7 are associated with earlier tumour stage and better clinical outcome in human breast cancer. BMC cancer. 2010:10:178.

8. Raccurt M, Tam SP, Lau P, Mertani HC, Lambert A, Garcia-Caballero T, et al Suppressor of cytokine signalling gene expression is elevated in breast carcinoma. British journal of cancer. 2003;89(3):524-32.

9. Smolkova B, Mego M, Horvathova Kajabova V, Cierna Z, Danihel L, Sedlackova T, et al. Expression of SOCS1 and CXCL12 Proteins in Primary Breast Cancer Are Associated with Presence of Circulating Tumor Cells in Peripheral Blood. Translational oncology. 2016;9(3):184-90.

10. Jiang M, Zhang WW, Liu P, Yu W, Liu T, Yu J. Dysregulation of SOCSMediated Negative Feedback of Cytokine Signaling in Carcinogenesis and Its Significance in Cancer Treatment. Frontiers in immunology 2017:8:70.

11. Darnell JE. Validating Stat3 in cancer therapy. Nat Med. 2005:11:595-6.

12. Lim EJ, Hong DY, Park JH, Joung YH, Darvin P, Kim SY, Na YM, Hwang TS, Ye SK, Moon ES, et al. Methylsulfonylmethane suppresses breast cancer growth by down-regulating STAT3 and STAT5b pathways. PLoS One. 2012;7:e33361.

13. Inagaki-Ohara $\mathrm{K}$, Kondo $\mathrm{T}$, Ito $\mathrm{M}$, Yoshimura $\mathrm{A}$. SOCS, inflammation, and cancer. JAKSTAT. 2013;2:e24053.

14. Farabegoli F, Ceccarelli C, Santini D, Taffurelli M. Suppressor of cytokine signalling 2 (SOCS-2) expression in breast carcinoma. J Clin Pathol. 2005;58:1046-50.

15. Haffner MC, Petridou B, Peyrat JP, Revillion F, Muller-Holzner E, Daxenbichler G, Marth C, Doppler W. Favorable prognostic value of SOCS2 and IGF-I in breast cancer. BMC Cancer. 2007;7:136.

16. Haan S, Wuller S, Kaczor J, Rolvering C, Nocker T, Behrmann I, Haan C. SOCS-mediated downregulation of mutant Jak2 (V617F, T875N and K539L) counteracts cytokine-independent signaling. Oncogene. 2009:28:3069-80.

17. Barclay JL, Anderson ST, Waters MJ, Curlewis JD. SOCS3 as a tumor suppressor in breast cancer cells, and its regulation by PRL. Int J Cancer. 2009:124:1756-66.

18. Kario E, Marmor MD, Adamsky K, Citri A, Amit I, Amariglio N, Rechavi G, Yarden Y. Suppressors of cytokine signaling 4 and 5 regulate epidermal growth factor receptor signaling. J Biol Chem. 2005;280:7038-48.

19. Masuda H, Zhang D, Bartholomeusz C, Doihara H, Hortobagyi GN, Ueno NT. Role of epidermal growth factor receptor in breast cancer. Breast Cancer Res Treat. 2012;136:331-45

20. Weniger MA, Melzner I, Menz CK, Wegener S, Bucur AJ, Dorsch K, Mattfeldt T, Barth TF, Moller P. Mutations of the tumor suppressor gene SOCS-1 in classical Hodgkin lymphoma are frequent and associated with nuclear phospho-STAT5 accumulation. Oncogene. 2006;25:2679-84. 